\title{
Intraocular pressure rise after small incision cataract surgery: a randomised intraindividual comparison of two dispersive viscoelastic agents
}

Georg Rainer, Rupert Menapace, Oliver Findl, Barbara Kiss, Vanessa Petternel, Michael Georgopoulos, Barbara Schneider

\begin{abstract}
Aim-To evaluate the effects of the dispersive viscoelastic agents Ocucoat (hydroxypropyl methylcellulose $2 \%$ ) and Viscoat (sodium chondroitin sulphate 4\%-sodium hyaluronate $3 \%$ ) on postoperative intraocular pressure (IOP) after bilateral small incision cataract surgery.

Methods-This prospective, randomised study comprised 80 eyes of 40 consecutive patients with age related cataract in both eyes scheduled for bilateral small incision cataract surgery. The patients were randomly assigned to receive Ocucoat or Viscoat during cataract surgery of the first eye. The second eye was operated later and received the other viscoelastic agent. Cataract surgery was performed with a temporal $3.2 \mathrm{~mm}$ sutureless posterior limbal incision, phacoemulsification, and implantation of a foldable silicone intraocular lens. The IOP was measured preoperatively as well as 6 hours, 20-24 hours, and 1 week postoperatively.
\end{abstract}

Results-At 6 hours after surgery the mean IOP increased by 4.6 (SD 5.1 ) $\mathrm{mm}$ $\mathrm{Hg}$ in the Ocucoat group $(\mathrm{p}<0.001)$ and by 8.6 (8.1) $\mathrm{mm} \mathrm{Hg}$ in the Viscoat group $(\mathbf{p}<0.001)$. The increase was significantly higher in the Viscoat group than in the Ocucoat group $(p=0.004)$. Intraocular pressure spikes of $30 \mathrm{~mm} \mathrm{Hg}$ or more occurred in two eyes in the Ocucoat and in nine eyes in the Viscoat group $(p=0.023)$; 20-24 hours and 1 week postoperatively the mean IOP was not statistically different.

Conclusion-These findings indicate that Viscoat causes a significantly higher IOP increase and significantly more IOP spikes than Ocucoat in the early period after small incision cataract surgery.

(Br f Ophthalmol 2001;85:139-142)

Dr Georg Rainer,

Department of

Ophthalmology, University

of Vienna, AKH-Vienna,

Waehringer Guertel 18-20,

A-1090 Vienna, Austria

georg.rainer@akh-wien.ac.at

Accepted for publication

7 August 2000

An increase in postoperative intraocular pressure (IOP) is a major postoperative complication within 24 hours after cataract surgery. ${ }^{1-3}$ Intraocular pressure spikes of $30 \mathrm{~mm} \mathrm{Hg}$ or higher in the early period after cataract surgery

Table 1 Biophysical properties of the viscoelastic agents

\begin{tabular}{lll}
\hline & Ocucoat & Viscoat \\
\hline Content & Hydroxypropyl & Sodium chondroitin sulphate \\
& methylcellulose 2\% & $4 \%$-sodium hyaluronate 3\% \\
Molecular weight (daltons) & 90000 & 600000 \\
Viscosity at zero shear rate (cps) & 4000 & 40000 \\
\hline
\end{tabular}

may be associated with pain, corneal epithelial oedema, and damage of the optic disc, particularly in patients with glaucoma. This has become a concern, since an increasing number of cataract patients are operated in an outpatient setting and discharged shortly after cataract surgery. A main cause for the postoperative IOP increase is that the viscoelastic agent remains in the eye, which causes a mechanical obstruction of the trabecular meshwork. $^{4}$

Ocucoat (hydroxypropyl methylcellulose) and Viscoat (sodium chondroitin sulphatesodium hyaluronate) are dispersive viscoelastic agents with low viscosity at zero shear rate (Table 1). The dispersive nature causes better adherence of the viscoelastic agent to the corneal endothelium, ${ }^{5}$ possibly resulting in better protection of the corneal endothelium against fluid turbulence and lens fragments during phacoemulsification. This has led to frequent use of such dispersive viscoelastic agents in routine small incision cataract surgery. In the USA, among ASCRS members, Viscoat is used as viscoelastic agent in about $30 \%,{ }^{6}$ and in Europe, among German language surgeons, Ocucoat or other hydroxypropyl methylcellulose preparations are used in about $45 \%$ of cataract surgeries. ${ }^{7}$

A potential drawback, however, is the difficulty of completely removing the dispersive viscoelastic agents at the end of surgery, possibly resulting in an increased postoperative IOP. For small incision phacoemulsification cataract surgery that currently is the most frequently performed technique, only one study reports on the effect of Viscoat, ${ }^{8}$ and there has been no study reporting the effect of Ocucoat on postoperative IOP.

We therefore conducted a prospective, randomised, patient and observer masked study to evaluate the effect of Ocucoat and Viscoat on postoperative IOP after bilateral small incision cataract surgery.

\section{Patients and methods}

This prospective randomised study comprised 80 eyes of 40 consecutive patients with bilateral age related cataract scheduled for small incision cataract surgery and implantation of an intraocular lens (IOL). The study protocol was approved by the ethics committee of the Vienna University School of Medicine. Written informed consent was obtained from all patients in the study. Exclusion criteria were previous ocular surgery, ocular hypertension (IOP higher than $22 \mathrm{~mm} \mathrm{Hg}$ ), and primary or 
Table 2 Preoperative and postoperative mean IOP ( $m m ~ H g), S D$, and range

\begin{tabular}{llll}
\hline Time & Ocucoat & Viscoat & p Value \\
\hline Preoperative & $14.0(2.8)(8-20)$ & $14.1(2.8)(8-19)$ & 0.602 \\
6 hours postop & $18.5(6.0)(9-39)$ & $22.7(8.7)(12-48)$ & 0.004 \\
20-24 hours postop & $14.0(3.5)(8-24)$ & $14.7(4.0)(9-24)$ & 0.551 \\
1 week postop & $13.5(2.7)(9-20)$ & $13.8(2.9)(7-20)$ & 0.313 \\
\hline
\end{tabular}

^Eyes that had an IOP of $30 \mathrm{~mm} \mathrm{Hg}$ or more at 6 hours postoperatively have been excluded.

Table 3 Mean IOP change ( $\mathrm{mm} \mathrm{Hg}$ ), SD, and range from preoperatively to 6 hours, 20-24 hours and 1 week postoperatively

\begin{tabular}{lllll}
\hline Time & Ocucoat & p Value & Viscoat & Value $^{\star \star}$ \\
\hline 6 hours postop & $4.6(5.1)(-3-21)$ & $<0.001$ & $8.6(8.1)(-2-32)$ & $<0.001$ \\
20-24 hours postop* & $0.3(3.3)(-6-7)$ & 0.510 & $0.8(3.0)(-4-8)$ & 0.130 \\
1 week postop & $-0.4(2.0)(-5-4)$ & 0.230 & $-0.2(2.3)(-4-4)$ & 0.584 \\
\hline
\end{tabular}

${ }^{\star}$ Eyes that had an IOP of $30 \mathrm{~mm} \mathrm{Hg}$ or more at 6 hours postoperatively have been excluded. $\star \star$ Difference from preoperatively.

secondary glaucoma. In each patient, the eye with the higher degree of cataract was operated first and randomly assigned to receive either Ocucoat (hydroxypropyl methylcellulose 2\%, Storz Inc) or Viscoat (sodium chondroitin sulphate 4\%-sodium hyaluronate 3\%, Alcon Inc) during surgery. The second eye was operated later and received the other viscoelastic agent. No attempt was made to mask the surgeon since the viscoelastic substances have typical handling features. Both groups included 20 right and 20 left eyes. Twenty seven patients were women, 13 were men. The mean patient age was 75.9 (SD 9.3, range 54-92) years.

All patients were operated by the same surgeon (RM). Approximately 1-2 hours before surgery diclofenac, phenylephrine $2.5 \%$, tropicamide $0.5 \%$, and cyclopentolate $1 \%$ eye drops were instilled. After peribulbar anaesthesia was administered, a temporal single plane $3.2 \mathrm{~mm}$ posterior limbal incision was performed. The assigned viscoelastic agent (Ocucoat or Viscoat) was then injected into the anterior chamber. Capsulorhexis, hydrodissection, and phacoemulsification of the nucleus was followed by aspiration of the cortical remnants and bimanual cleaning of the capsular bag via three paracenteses. The capsular bag was then expanded with the assigned viscoelastic agent, and a foldable silicone three piece IOL was implanted in the capsular bag. The viscoelastic agent was aspirated thoroughly from the retrolental space, the capsule fornix, and the anterior chamber using an I/A tip. First, the proximal optic edge was tilted up with a spatula and the I/A tip inserted behind the optic. After the central portion of the viscoelastic substance was removed, the I/A tip was swept across and along the capsule equator to capture peripheral residuals. The I/A tip was then guided into the anterior chamber and the optic repositioned. While the aspiration opening was rotated right, left and posteriorly, the viscoelastic agent was circumferentially removed from the prelental as well as from the retroiridal and preiridal spaces. The surgeon was careful not to approach the delicate structures of the endothelium and the chamber angle too closely. Consequently, the residual film coating these structures was often observed to persist. Finally, the I/A tip was positioned on the centre of the optic and, while directing the aspiration opening upwards and pressing the tip down on the optic, the anterior chamber was rinsed before retracting the I/A tip. The incision was left sutureless. No miotic agent was used intracamerally, and no antiglaucomatous agent was instilled immediately after cataract surgery. Capsule rupture did not occur in any patient. After surgery, the eye was patched with prednisolone ointment. Treatment after the 20-24 hour visit consisted of diclofenac and prednisolone acetate $0.5 \%$ eye drops four times a day.

The baseline IOP was measured by Goldmann applanation tonometry on the day before surgery. The IOP was again measured with the same Goldmann applanation tonometer 6 and 20-24 hours after surgery. The ophthalmologist who measured the IOP was masked to the group assignment. If the IOP was $30 \mathrm{~mm} \mathrm{Hg}$ or higher at the 6 hour visit, topical (dorzolamide, timolol, or both) or systemic (actetazolamide) antiglaucomatous agents were administered and the 20-24 hour IOP value was not used for statistical analysis. A routine follow up including IOP measurement was performed 1 week after surgery.

Group comparisons of the preoperative and postoperative IOP and of the mean IOP changes from preoperatively to 6 hours, 20-24 hours and 1 week postoperatively were made with paired $t$ tests. Preoperative values were compared with those after 6 hours, 20-24 hours, and 1 week separately for each group, also using paired $t$ tests. The proportion of patients with an IOP of $30 \mathrm{~mm} \mathrm{Hg}$ or higher was compared with the $\chi^{2}$ test. A p value $<0.05$ was considered statistically significant.

\section{Results}

Table 2 shows the mean preoperative and postoperative IOP. There was no significant "between group" difference in preoperative IOP. At 6 hours postoperatively, the mean IOP was significantly higher in the Viscoat group than in the Ocucoat group. At 20-24 hours and at 1 week postoperatively, there was no significant between group difference.

Mean IOP changes from preoperatively to 6 hours, 20-24 hours, and 1 week postoperatively are listed in Table 3. At 6 hours, the mean IOP increased significantly in both groups. At 20-24 hours and at 1 week there was no significant change in either group.

Figure 1 compares the mean IOP changes in the two groups. At 6 hours, the mean IOP increase was significantly higher in the Viscoat than in the Ocucoat group $(p=0.004)$. At 20-24 hours and at 1 week, there were no between group differences $(p=0.662$ and $\mathrm{p}=0.650$, respectively).

Table 4 shows the number, percentage, and IOP in eyes with an IOP increase of $30 \mathrm{~mm} \mathrm{Hg}$ or higher at 6 hours after surgery. There were significantly more eyes with an IOP increase of $30 \mathrm{~mm} \mathrm{Hg}$ or higher in the Viscoat group than in the Ocucoat group. The highest IOP values were $48 \mathrm{~mm} \mathrm{Hg}$ in the Viscoat group and 39 $\mathrm{mm} \mathrm{Hg}$ in the Ocucoat group. 


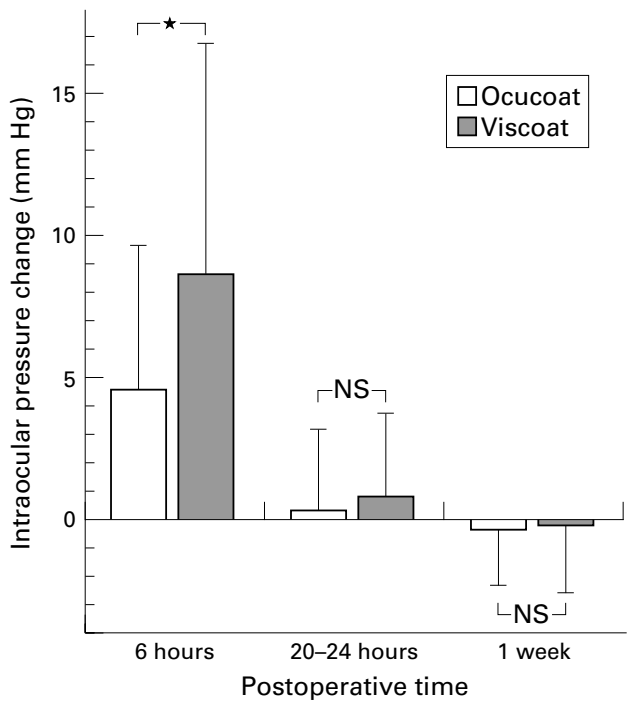

Figure 1 Group comparison of the mean IOP change (mm Hg) from preoperatively to 6 hours, 20-24 hours, and 1 week postoperatively. At 20-24 hours postoperatively, the eyes that had an IOP of $30 \mathrm{~mm} \mathrm{Hg}$ or more at 6 hours have been excluded ( ${ }^{*} p=0.004 ;$ ns $=$ not significant).

Table 4 Number, percentage, and IOP values of eyes with an IOP of $30 \mathrm{~mm} \mathrm{Hg}$ or higher at 6 hours after surgery

\begin{tabular}{llll}
\hline & Ocucoat & Viscoat & $p$ Value \\
\hline Number (\%) of eyes & $2(5 \%)$ & $9(23 \%)$ & 0.023 \\
IOP (mm Hg) & 31,39 & $\begin{array}{l}30,31,31,34,34, \\
\end{array}$ & - \\
\hline
\end{tabular}

\section{Discussion}

Viscoelastic agents are widely used in small incision cataract surgery. Their use has several advantages, and especially dispersive viscoelastic agents are thought to protect the corneal endothelium from extensive damage during the phacoemulsification procedure. However, viscoelastic agents have the disadvantage of causing an increase in IOP. This has become a major concern, since an increasing number of cataract surgeries is performed on an outpatient basis and patients are often discharged shortly after surgery. In this study, we evaluated the effect of two commonly used dispersive viscoelastic agents on the IOP after small incision cataract surgery.

Our findings indicate that in the early postoperative period after small incision cataract surgery, Viscoat causes a significantly higher IOP increase and significantly more IOP spikes than Ocucoat. At 6 hours postoperatively, the mean IOP increased by about 9 $\mathrm{mm} \mathrm{Hg}$ in the Viscoat group and by about 5 $\mathrm{mm} \mathrm{Hg}$ in the Ocucoat group. IOP spikes of 30 $\mathrm{mm} \mathrm{Hg}$ or higher occurred in nine eyes in the Viscoat group compared with two eyes in the Ocucoat group. At 20-24 hours the mean IOP decreased to preoperative values in both groups. However, in this study no IOP lowering medication was given at the end of surgery. The fact that both viscoelastic agents caused a significant IOP increase and IOP spikes of $30 \mathrm{~mm} \mathrm{Hg}$ or more, argues for a prophylactic use of IOP lowering medication.

In a previous study ${ }^{8}$ we compared the effect of Healon5, a cohesive viscoelastic agent, and Viscoat on postoperative IOP after small incision cataract surgery which was performed by the same surgeon (RM). At 6 hours postoperatively, the IOP increase was about $10 \mathrm{~mm}$ $\mathrm{Hg}$ in the Viscoat group which is comparable with the result of the present study. There has been no other report on postoperative IOP after small incision cataract surgery with Viscoat.

Moreover, there has been no report on postoperative IOP after small incision cataract surgery with Ocucoat. The postoperative IOP increase of about $5 \mathrm{~mm} \mathrm{Hg}$ at 6 hours postoperatively with Ocucoat seems to be similar to that of Healon (sodium hyaluronate $1 \%)^{9}$ and Healon5 (sodium hyaluronate $2.3 \%$ ). ${ }^{8}$

Articles reporting the effect of Viscoat or Ocucoat on postoperative IOP used manual extracapsular cataract extraction $(\mathrm{ECCE})^{10-16}$ or phacoemulsification cataract surgery with a $7 \mathrm{~mm}$ incision. $^{317}$ In two further studies antiglaucomatous agents were used and the IOP was measured at 1 day postoperatively only. ${ }^{18}{ }^{19}$ However, these reports are difficult to compare and often contradictory, since the postoperative IOP varies interindividually and with the surgical technique.

The mechanism of postoperative IOP increase is not yet fully understood. A major reason for the postoperative IOP increase seems to be the amount of the remaining viscoelastic agent at the end of surgery. It is assumed that the remaining viscoelastic agent mechanically obstructs the trabecular outflow pathway and hence decreases the outflow facility. ${ }^{4}$ In order to avoid a postoperative IOP increase, a thorough removal of viscoelastic agent is vital. Surgical techniques for the removal of viscoelastic substances, especially from behind the IOL, have been described, ${ }^{20-22}$ but a complete prevention of a postoperative IOP increase could not be achieved with any technique.

In our study, both Ocucoat and Viscoat were equally removed with great care from the anterior chamber as well as from behind the IOL at the end of the surgery. However, it was nearly impossible to completely remove both viscoelastic agents without injuring the endothelium and other vulnerable structures of the eye. Assuming that the amounts of the remaining viscoelastic substances were similar in our study, the difference in postoperative IOP increase between the two viscoelastic agents might be explained by differences in their biophysical properties. The clearance of the viscoelastic agent through the trabecular meshwork is believed to be dependent upon the viscosity and molecular weight of the used materials. ${ }^{11}$ Theoretically, the lower the viscosity and the molecular weight of the viscoelastic agent, the faster is the clearance through the trabecular meshwork. In accordance with this theory, in our study Ocucoat which is less viscous and has a lower molecular weight than Viscoat caused less IOP increase. The lower viscosity of Ocucoat compared with Viscoat, may, however, have the disadvantage of poorer endothelial cell protection.

In conclusion, our study shows that in the early postoperative period after small incision cataract surgery Viscoat caused a significantly 
higher IOP increase and significantly more IOP spikes than Ocucoat. Although the viscoelastic agents were removed thoroughly, both Ocucoat and Viscoat caused a significant IOP increase compared with the preoperative IOP. Therefore IOP monitoring is necessary after small incision cataract surgery, and the use of IOP lowering medications is recommended, particularly in patients with compromised optic discs.

None of the authors has a proprietary interest in any product mentioned.

1 Percival SPB. Complications from use of sodium hyaluronate (Healonid) in anterior segment surgery. $\mathrm{Br} \mathcal{F}$ Ophthatmol 1982;66:714-16.

2 Passo MS, Ernest JT, Goldstick TK. Hyaluronate increases intraocular pressure when used in cataract extraction. $\mathrm{Br} \mathcal{F}$ Ophthalmol 1985;69:572-5.

3 Böhmer TG, Lagreze WA, Funk J. Intraocular pressure rise after phacoemulsification with posterior chamber lens implantation: effect of prophylactic medication, wound implantation: effect of prophylactic medication, wound 1995;79:809-13.

4 Benson FG, Patterson MM, Epstein DL. Obstruction of aqueous outflow by sodium hyaluronate in enucleated aqueous outflow by sodium hyaluronate in
human eyes. Am 7 Ophthalmol 1983;95:668-72.

5 Poyer JF, Chan KY, Arshinoff SA. New method to measure the retention of viscoelastic agents on a rabbit corneal endothelial cell line after irrigation and aspiration. $f$ Cataract Refract Surg 1998;24:84-90.

6 Leaming DV. Practice styles and preferences of ASCRS members-1997 survey. $\mathscr{f}$ Cataract Refractive Surg 1998;24 552-61.

7 Wenzel M, Ohrloff C, Duncker G. In: Ohrloff C, Kohnen T, Duncker G, eds. II. Kongress der Deutschsprachigen Gesellschaft für Intraokularlinsen-Implantation und refraktive Chirurgie. Berlin, Heidelberg, New York: Springer, 1996:15-20.

8 Rainer G, Menapace R, Findl O, et al. Intraocular pressure after small incision cataract surgery with Healon 5 and Viscoat. 7 Cataract Refract Surg 2000; 26:272-7.

9 Rainer G, Menapace R, Schmetterer K, et al. Effect of dorzolamide and latanoprost on intraocular pressure following small incision cataract surgery. $\mathcal{F}$ Cataract Refract Surg 1999;25:1624-9.

10 Fry LL. Postoperative intraocular pressure rises: a comparison of Healon, Amvisc, and Viscoat. $\mathcal{F}$ Cataract Refract Surg 1989;15:415-20

11 Lane SS, Nayler DW, Kullerstrand LJ, et al. Prospective comparison of the effects of Occucoat, Viscoat, and Healon on intraocular pressure and endothelial cell loss. 7 Cataract Refract Surg 1991;17:21-6.

12 Barron BA, Busin M, Page C, et al. Comparison of the effects of Viscoat and Healon on postoperative intraocular pressure. Am f Ophthalmol 1985;100:377-84.

13 Henry JC, Olander K. Comparison of the effect of four viscoelastic agents on early postoperative intraocular pressure. 7 Cataract Refract Surg 1996;22:960-6.

14 MacRae SM, Edelhauser HF, Hyndiuk RA, et al. The effects of sodium hyaluronate, chondroitin sulfate, and methylcellulose on the corneal endothelium and intraocular pressure. Am f Ophthalmol 1983;95:332-41.

15 Liesegang TJ, Bourne WM, Istrup DM. The use of hydroxypropyl methylcellulose in extracapsular cataract extraction with intraocular lens implantation. $A m$ f Ophthalmol 1986;102:723-6.

16 Dada VK, Sindhu N, Sachdev MS. Postoperative intraocular pressure changes with use of different viscoelastics. Ophthalmic Surg 1994;25:540-4.

17 Hütz WW, Eckhardt HB, Kohnen T. Comparison of viscoeastic substances used in phacoemulsification. 7 Cataract Refract Surg 1996;22:955-9.

18 Probst LE, Nichols BD. Corneal endothelial and intraocular pressure changes after phacoemulsification with Amvisc Plus and Viscoat. I Cataract Refract Surg 1993;19:725-30.

19 Probst LE, Hakim OJ, Nichols BD. Phacoemulsification with aspirated or retained Viscoat. I Cataract Refract Surg 1994;20:145-9.

20 Wedrich A, Menapace R. Intraocular pressure following small-incision cataract surgery and polyHEMA posterior chamber lens implantation. A comparison between acetylcholine and carbachol. 7 Cataract Refract Surg 1992;18: choline 5 .

21 Kohnen T, von Ehr M, Schütte E, et al. Evaluation of intraocular pressure with Healon and Healon GV in sutureless cataract surgery with foldable lens implantation. f Cataract Refract Surg 1996;22:227-37.

22 Jacobi PC, Engels B, Dietlein TS, et al. Effect of trabecular aspiration on early intraocular pressure rise after cataract surgery. 7 Cataract Refract Surg 1997;23:923-9. 